Berman, 1961; Brown et al., 1962; Clayman et al., 1968). The response appears unpredictable. The lowering of acid secretion achieved by irradiation gives the underlying lesion an opportunity to heal, and it may be that once healed a lesion is less likely to recur.

The clinical status that led our patients to radiotherapy precluded extensive follow-up; indeed, the select nature of the series and the poor health of the patients is reflected in the $25 \%$ mortality. We do not recommend irradiation as a means of lowering acid output in the under-60s unless associated conditions threaten life or surgery is contraindicated. In the present study four patients were below this age and two of these were under 40. Of the two youngest patients one was an alcoholic vagrant with active pulmonary tuberculosis and the other had already had a gastroenterostomy and two partial gastrectomies by the time he presented with a further jejunal ulcer. No evidence of a gastrin-secreting adenoma was found in this patient. The third patient was unfit for surgery because of a previous pneumonectomy for tuberculosis, and the fourth, a 57-year-old man, had had two gastrectomies and a vagotomy and was subsequently found to have the Zollinger-Ellison syndrome. This patient had symptomatic relief for the first four years after his radiotherapy, which was given in 1955 before the Zollinger-Ellison syndrome was recognized. Other observers (Clayman et al., 1968) of patients with gastrin-secreting adenomas have suggested that they tend to be refractory to gastric irradiation.

No patient developed nephritis after radiotherapy. Two patients had chronic renal impairment before radiotherapy and neither showed further deterioration in renal function. The poor long-term prognosis of the patients in this selected series was such that the hazard of nephritis eight to 18 years after therapy was unlikely to prove a major issue. Where possible creatinine clearance tests were carried out before and after irradiation and to date no evidence of any appreciable deterioration in renal function has been evident.

Our experience suggests that gastric irradiation provides a good chance of relief of symptoms and healing of the lesions associated with peptic ulceration and peptic oesophagitis; it does this without significant morbidity. We therefore recommend the use of radiotherapy in elderly patients with associated disease.

\section{References}

Bassler, A. (1909). Medical Times, 37, 259.

Brown, C. H., Sahba, M., and Levin, E. (1962). American fournal of Gastroenterology, 38, 278.

Bruegel, C. (1919). Münchener medizinische Wochenschrift, 64, 379.

Clayman, C. B., Palmer, W. L., and Kirsner, J. B. (1968). Gastroenterology, $55,403$.

Griffiths, J. M. T. (1972). Gerontologia Clinica, 14, 282

Hedfeld, A. (1948). Strahlentherapie, 77, 387.

Klein, H. C., and Berman, N. E. (1961). Fournal of the American Medica Association, 176, 98.

Kruglikowa, R. K., Katscher, M. L., and Aviossor, M. L. (1936). Roentgenpraxis, 8, 179.

Levin, E., et al. (1954). Fournal of the American Medical Association, 156, 1383

Levin, E., et al. (1957). Gastroenterology, 32, 42.

Ricketts, W. E., et al. (1948). Gastroenterology, 11, 789.

Thompson, P. L., et al. (1971). Quarterly fournal of Medicine, 40, 145.

\title{
Transthoracic Electrical Impedance in Cases of High-altitude Hypoxia
}

\author{
SUJOY B. ROY, \\ V. BALASUBRAMANIAN, \\ M. R. KHAN, \\ V. S. KAUSHIK, \\ S. C. MANCHANDA, \\ S. K. GUHA
}

British Medical fournal, 1974, 3, 771-775

\section{Summary}

Changes in transthoracic electrical impedance (T.E.I.) due to high-altitude hypoxia $(3,658 \mathrm{~m})$ have been measured in 20 young, healthy Indian soldiers. They were first studied at sea level $(198 \mathrm{~m})$ and then rapidly transported by air to $3,658 \mathrm{~m}$, where they were studied daily from day 1 to day 5 and then on days 8 and 10. The mean ( \pm S.D.) T.E.I. at sea level $(34.6 \pm 0.6 \Omega)$ fell sharply to $29 \cdot 6 \pm 0.8 \Omega, 30 \cdot 3 \pm 0.9 \Omega$, and $30.5 \pm 1 \cdot 1 \Omega$ on days 1,2 , and 3 $(P<0.001)$ and levelled off at $31.5 \pm 0.7 \Omega$ on day 10, which was comparable to the mean value obtained in 13 persons permanently resident at high altitude $(32 \cdot 2 \pm 0 \cdot 7 \Omega)$. Five sea-level residents who had acute mountain sickness (A.M.S.) or high-altitude pulmonary oedema (H.A.P.O.) had a still lower mean value $(22 \cdot 5 \pm 1 \cdot 1 \Omega)$. One normal

All India Institute of Medical Sciences, New Delhi 16, India SUJOY B. ROY, M.B., F.R.C.P., Professor and Head of Department of Cardiology

M. R. KHAN, M.sc., Research Scholar in Biomedical Engineering V. S. KAUSHIK, M.D., D.M.(CARD.), Registrar in Cardiology

S. C. MANCHANDA, M.D., D.M.(CARD.), Lecturer in Cardiology

S. K. GUHA, M.TrCH., PH.D., Professor of Biomedical Engineering

Directorate General Armed Forces Medical Services, New Delhi V. BALASUBRAMANIAN, M.D., Research Pool Officer healthy subject who at sea level had a T.E.I. of $34 \cdot 7 \Omega$ developed H.A.P.O. when the T.E.I. fell to $21 \cdot 1 \Omega$. Ninety minutes after the administration of $80 \mathrm{mg}$ of intravenous frusemide the value increased to $35.5 \Omega$. In another subject with A.M.S. who received $40 \mathrm{mg}$ of frusemide intravenously the T.E.I. rose from 21.9 to $33.2 \Omega$.

Since the study was non-invasive the changes in impedance could not be correlated objectively with alterations in either pulmonary blood volume or pulmonary extravascular water space. In the subject, however, with X-ray evidence of H.A.P.O. and a low T.E.I. intravenous frusemide produced a marked rise in T.E.I. together with clearing of the chest $x$-ray picture within 24 hours, indicating an inverse relationship between impedance and thoracic fluid volume. It is suggested that with further objective verification in man the measurement of T.E.I. may be a potentially promising technique for the early detection of increased pulmonary fluid volume.

\section{Introduction}

In a previous study (Roy et al., 1968) the pulmonary blood volume in healthy volunteers was shown to increase by about $80 \%$ three or four days after their arrival by air at an altitude of $3,658 \mathrm{~m}$. The method used to estimate the pulmonary blood volume, however, had two inherent defects-(1) only the intravascular blood volume could be measured, and (2) since the technique was invasive repeated observations on the same subject were not feasible. Pomerantz et al. (1970) and Van De Water 
et al. $(1970,1973)$ then showed that alterations in thoracic fluid volume could be reliably detected by changes in electrical impedance.

The aim of the present study was to find whether transthoracic electrical impedance (T.E.I.) shows a consistent pattern of change in subjects exposed to high-altitude hypoxia. T.E.I. was measured in healthy male volunteers at sea level and then serially at $3,658 \mathrm{~m}$. The T.E.I. of persons permanently resident at high altitude and of sea-level residents suffering from acute mountain sickness (A.M.S.) or high-altitude pulmonary oedema (H.A.P.O.) was also estimated at high altitude.

\section{Theory of T.E.I. and Technique for Measurement}

Biological tissues contain salts, a relatively fixed proportion of which are dissociated into their corresponding cations and anions. The conductance (G) of a current (I) through biological tissue is dependent on the number of these ions. Since this number is usually constant for a known volume of water, especially the extracellular fluid, it is theoretically possible to relate conductance to the total volume $(\mathrm{V})$ of that tissue. Any change in conductance will therefore reflect a change in volume $-\Delta V / V=\Delta G / G$.

Conductance can be defined in terms of its reciprocal resistance (R). Thus $G=I / R$. Resistance is related to current and voltage (E)$\mathbf{R}=\mathrm{E} / \mathrm{I}$. Resistance may therefore be determined by establishing a fixed-current field across tissue and measuring the change in voltage. For this purpose a high-frequency alternating current (A.C.) is normally used; thus it is the A.C. equivalent of resistance, impedance $(Z)$, which is actually being measured.

The instrument used to measure T.E.I. in this study (designed, developed, and built by the biomedical engineering unit of the Indian Institute of Technology, New Delhi) comprised a circuit consisting of a $20-\mathrm{kHz}$ oscillator coupled through a transformer to a modified Kelvin-type bridge. The current applied across the thorax was kept constant at $200 \mu \mathrm{A}$. Impedance was measured by balancing the bridge and observing the result on an electronic detector through an amplifier. A tetrapolar electrode system was used with band electrodes $1-\mathrm{cm}$ wide made of copper shield. The electrodes were sited at constant anatomical landmarks (fig. 1). Electrodes $I_{1}$ and $E_{1}$ were placed just above and below the cricoid cartilage, electrode $E_{2}$ was placed at the level of the xiphisternum, and electrode $I_{2}$ was placed $5 \mathrm{~cm}$ below the xiphisternum. Electrodes $I_{1}$ and $I_{2}$ were used to pass the current and electrodes $E_{1}$ and $E_{2}$ to record the drop in voltage between these two points. At the low ferquency used the capacitative reactance was negligible and constituted a constant component of impedance, the major balance being obtained by resistive balancing. Impedance was calculated as follows:

$$
\frac{\mathrm{R}}{1+(\omega \mathrm{RC})^{2}}
$$

where $R$ is the resistive component in $\Omega, C$ is the capacitance in $F$, and $\omega=2 \pi \mathrm{f}$, where $\mathrm{f}$ is the frequency in $\mathrm{Hz}$. All the studies were performed in the fasting state, the room temperature being maintained at $30 \pm 1^{\circ} \mathrm{C}$ both at sea level and at the high altitude.

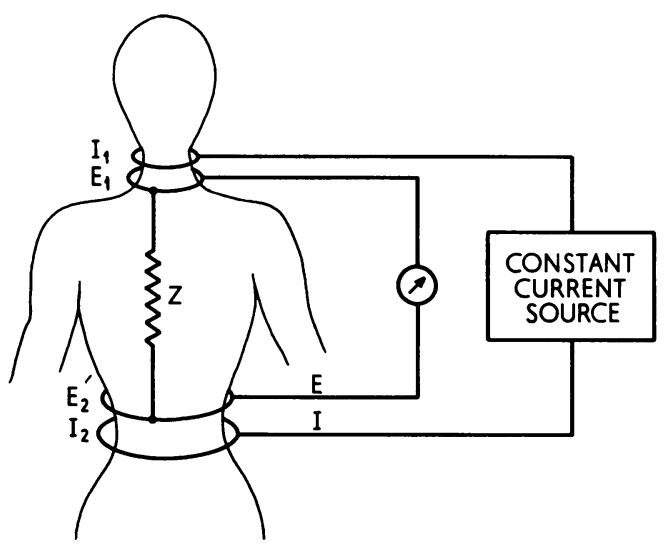

FIG. 1-Placement of copper electrodes. $I_{1}$ and $E_{1}$ sited just above and below cricoid cartilage, $E_{2}$ sited at level of xiphisternum, and $I_{2}$ sited $5 \mathrm{~cm}$ below xiphisternum. (See text.) $\mathrm{Z}=$ Impedance.
In order to standardize the technique only the lowest readings were recorded. These occur at the end of expiration and correspond to the functional residual capacity (Allison et al., 1964). Thus in this way the variation in T.E.I. with respiration ( 1.0 to $2.0 \Omega$ during a vital capacity manoeuvre) is avoided and reproducibility is achieved. Measurements were thus made with the breath held in expiration by the same observers using the same equipment at both places.

The means and S.D. were calculated and analysed with Student's paired $t$ test.

\section{Subjects}

T.E.I. was measured at sea level $(198 \mathrm{~m})$ in 20 healthy male volunteers from the Indian army aged 19 to 35 (mean 25) years who had never been to an altitude of over $2,000 \mathrm{~m}$. They were then transported by air within one hour to an altitude of $3,658 \mathrm{~m}$, where each subject was studied daily from day 1 to day 5 and then on days 8 and 10 . One of the volunteers (subject 5) developed H.A.P.O. on the second day. He was excluded from the normal series but included with six other sea-level residents suffering from A.M.S. or H.A.P.O. in whom T.E.I. was measured serially for six days.

To obtain baseline values for persons permanently resident at high altitudes T.E.I. was measured on two occasions in 13 men aged 19 to 34 (mean 24) years of comparable weight (61 to $65 \mathrm{~kg}$ ) and height (163 to $170 \mathrm{~cm}$ ) who together with three generations of their forbears had been born at an altitude of $3658 \mathrm{~m}$ or higher and had never visited the plains.

\section{Results}

\section{NORMAL SEA-LEVEL RESIDENTS}

The mean T.E.I. at sea level for the normal volunteers was $34 \cdot 6 \pm$ S.D. $0.6 \Omega$ (range $32 \cdot 9$ to $35 \cdot 2 \Omega$ ) (table I, fig. 2). This fell significantly on the day of arrival at the high altitude $(P<0.001)$. The values then gradually improved, reaching a steady level on the tenth day. The differences in T.E.I. at the high altitude compared with at sea level were statistically significant $(P<0.001)$.

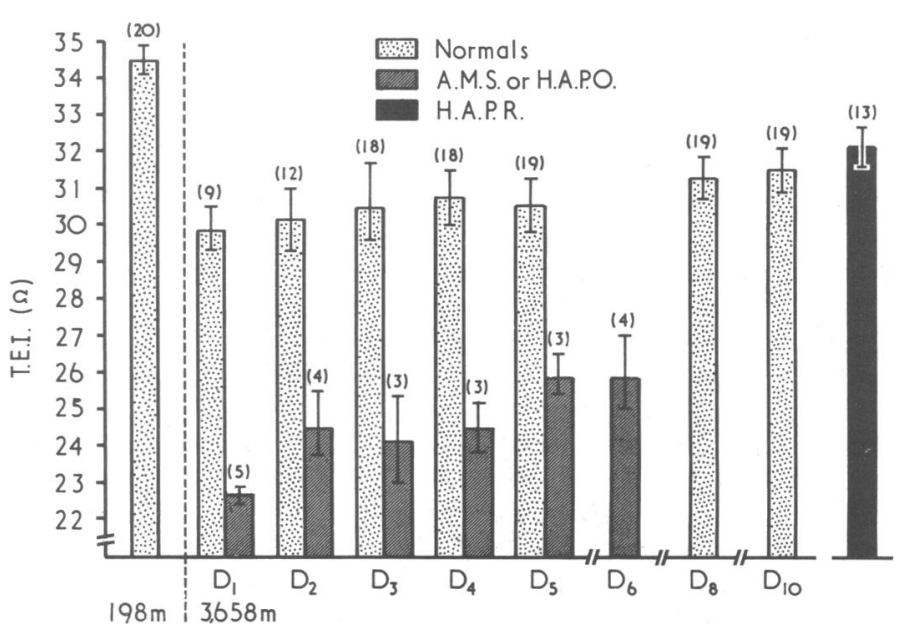

FIG. 2-Mean T.E.I. in 20 normal healthy volunteers at sea level (198 $\mathrm{m}$ ) and at high altitude $(3,658 \mathrm{~m})$ from day 1 to day 5 and on days 8 and 10 , in five subjects suffering from A.M.S. or H.A.P.O. from day $1 \mathrm{t}$ ) day 6 , and in 13 permanent residents of high altitude (H.A.P.R.). Numbers of subjects studied are shown in parentheses.

\section{SUBJECTS DEVELOPING H.A.P.O. OR A.M.S.}

Case 1.-A 27-year-old soldier (subject 5) developed breathlessness at rest, severe headache, nausea, and marked anorexia on his second day at high altitude. Clinical and radiological examination (fig. 3) confirmed the diagnosis of H.A.P.O. His T.E.I. had fallen from 
TABLE I-Serial T.E.I. Values in Normal Subjects Observed at Sea Level and after Exposure to High Altitude. Values are expressed in $\Omega$

\begin{tabular}{|c|c|c|c|c|c|c|c|c|c|}
\hline \multirow{2}{*}{$\begin{array}{c}\text { Subject } \\
\text { No. }\end{array}$} & \multirow{2}{*}{$\begin{array}{c}\text { Age } \\
\text { (Years) }\end{array}$} & \multirow{2}{*}{$\begin{array}{c}\text { Sea } \\
\text { Level }\end{array}$} & \multicolumn{7}{|c|}{ Day of Exposure to High Altitude } \\
\hline & & & 1 & 2 & 3 & 4 & 5 & 8 & 10 \\
\hline $\begin{array}{r}1 \\
2 \\
3 \\
4 \\
5 \\
6 \\
7 \\
8 \\
9 \\
10 \\
11 \\
12 \\
13 \\
14 \\
15 \\
16 \\
17 \\
18 \\
19 \\
20\end{array}$ & $\begin{array}{l}27 \\
22 \\
20 \\
32 \\
27 \\
25 \\
22 \\
22 \\
21 \\
23 \\
23 \\
24 \\
35 \\
26 \\
28 \\
25 \\
23 \\
26 \\
21 \\
19\end{array}$ & $\begin{array}{l}34 \cdot 9 \\
35 \cdot 0 \\
32 \cdot 9 \\
33 \cdot 1 \\
34 \cdot 7 \\
35 \cdot 0 \\
34 \cdot 6 \\
34 \cdot 2 \\
34 \cdot 8 \\
34 \cdot 8 \\
34 \cdot 0 \\
34 \cdot 9 \\
34 \cdot 4 \\
34 \cdot 4 \\
35 \cdot 2 \\
34 \cdot 9 \\
35 \cdot 0 \\
34 \cdot 9 \\
34 \cdot 8 \\
34 \cdot 8\end{array}$ & $\begin{array}{l}29 \cdot 0 \\
29 \cdot 4 \\
29 \cdot 4 \\
31 \cdot 2 \\
28 \cdot 5 * \\
29 \cdot 4 \\
29 \cdot 1 \\
30 \cdot 2 \\
31 \cdot 1 \\
29 \cdot 8 \\
\text { N.D. } \\
\text { N.D. } \\
\text { N.D. } \\
\text { N.D. } \\
\text { N.D. } \\
\text { N.D. } \\
\text { N.D. } \\
\text { N.D. } \\
\text { N.D. } \\
\text { N.D. }\end{array}$ & $\begin{array}{l}31 \cdot 7 \\
29 \cdot 7 \\
30 \cdot 4 \\
29 \cdot 7 \\
21 \cdot 1 . \\
30 \cdot 8 \\
\text { N.D. } \\
\text { N.D. } \\
\text { N.D. } \\
\text { N.D. } \\
\text { N.D. } \\
28 \cdot 7 \\
28 \cdot 8 \\
30 \cdot 4 \\
30 \cdot 0 \\
31 \cdot 6 \\
31 \cdot 1 \\
30.7 \\
\text { N.D. } \\
\text { N.D. }\end{array}$ & $\begin{array}{l}31 \cdot 4 \\
29 \cdot 7 \\
30.4 \\
29 \cdot 7 \\
33 \cdot 0^{*} \\
30 \cdot 8 \\
30 \cdot 6 \\
29 \cdot 0 \\
31 \cdot 4 \\
27 \cdot 2 \\
29 \cdot 8 \\
31 \cdot 4 \\
31 \cdot 1 \\
31 \cdot 2 \\
31 \cdot 4 \\
31 \cdot 6 \\
31 \cdot 9 \\
29 \cdot 7 \\
30 \cdot 9 \\
\text { N.D. }\end{array}$ & $\begin{array}{l}31 \cdot 9 \\
31 \cdot 4 \\
30 \cdot 8 \\
30 \cdot 8 \\
31 \cdot 3 \\
31 \cdot 1 \\
31 \cdot 1 \\
29 \cdot 8 \\
32 \cdot 4 \\
30 \cdot 0 \\
29 \cdot 9 \\
30 \cdot 5 \\
\text { N.D. } \\
31 \cdot 8 \\
31 \cdot 0 \\
30 \cdot 4 \\
30 \cdot 5 \\
30 \cdot 1 \\
31 \cdot 2 \\
31 \cdot 4\end{array}$ & $\begin{array}{l}32 \cdot 3 \\
30.9 \\
29.7 \\
31.4 \\
30 \cdot 6 \\
30 \cdot 9 \\
30.9 \\
28 \cdot 1 \\
31 \cdot 4 \\
30 \cdot 2 \\
30 \cdot 6 \\
30.9 \\
\text { N.D. } \\
30.4 \\
31 \cdot 2 \\
31 \cdot 2 \\
30.1 \\
30 \cdot 4 \\
30 \cdot 4 \\
30.6\end{array}$ & $\begin{array}{l}32 \cdot 4 \\
31 \cdot 3 \\
30.6 \\
31.9 \\
31.4 \\
31 \cdot 3 \\
31 \cdot 3 \\
29 \cdot 2 \\
32 \cdot 4 \\
30 \cdot 6 \\
31 \cdot 4 \\
31.9 \\
\text { N.D. } \\
30.9 \\
31.6 \\
31.9 \\
30 \cdot 8 \\
31.1 \\
31.4 \\
31.2\end{array}$ & $\begin{array}{l}32 \cdot 3 \\
30.8 \\
31 \cdot 4 \\
32 \cdot 2 \\
31.7 \\
30.4 \\
31.6 \\
30.1 \\
32 \cdot 2 \\
31 \cdot 2 \\
38.0 \\
32.4 \\
\text { N.D. } \\
31 \cdot 6 \\
32.2 \\
32.2 \\
31.2 \\
30.8 \\
31.0 \\
31.4\end{array}$ \\
\hline \multicolumn{2}{|c|}{ No. of observations .. } & 20 & 9 & 12 & 18 & 18 & 19 & 19 & 19 \\
\hline \multicolumn{2}{|c|}{ Mean T.E.I. \pm S.D. } & $34.6 \pm 0.6$ & $29 \cdot 6 \pm 0 \cdot 8$ & $30.3 \pm 0.9$ & $30 \cdot 5 \pm 1 \cdot 1$ & $30.9 \pm 0.7$ & $30.6 \pm 0.8$ & $31 \cdot 3 \pm 0.7$ & $31.5 \pm 0.7$ \\
\hline \multicolumn{2}{|l|}{$\mathbf{P}$} & & $<0.001$ & $<0.001$ & $<0.001$ & $<0.001$ & $<0.001$ & $<0.001$ & $<0.001$ \\
\hline
\end{tabular}

*Excluded from calculation of mean values as subject developed acute H.A.P.O. and received treatment.

tDeveloped allergy to electrolyte jelly.

N.D. = Not done.

TABLE II-Serial T.E.I. Values in Patients with A.M.S. and H.A.P.O.

\begin{tabular}{|c|c|c|c|c|c|c|c|c|}
\hline \multirow{2}{*}{$\begin{array}{c}\text { Subject } \\
\text { No. }\end{array}$} & \multirow{2}{*}{$\begin{array}{c}\text { Age } \\
\text { (Years) }\end{array}$} & \multirow[t]{2}{*}{ Disease } & \multicolumn{6}{|c|}{ Days after Onset of Symptoms } \\
\hline & & & 1 & 2 & 3 & 4 & 5 & 6 \\
\hline $\begin{array}{l}21 \\
22 \\
23 \\
24 \\
25\end{array}$ & $\begin{array}{l}37 \\
40 \\
23 \\
27 \\
31\end{array}$ & $\begin{array}{l}\text { A.M.S. } \\
\text { A.M.S. } \\
\text { H.A.P.O. } \\
\text { H.A.P.O. } \\
\text { H.A.P.O. }\end{array}$ & $\begin{array}{l}21 \cdot 1 \\
23 \cdot 0 \\
22 \cdot 3 \\
24 \cdot 0 \\
21 \cdot 9\end{array}$ & $\begin{array}{l}25 \cdot 1 \\
25 \cdot 2 \\
23 \cdot 4 \\
24 \cdot 0\end{array}$ & $\begin{array}{l}25 \cdot 1 \\
22 \cdot 6 \\
24 \cdot 5\end{array}$ & $\begin{array}{l}24 \cdot 0 \\
24 \cdot 0 \\
25 \cdot 0\end{array}$ & $\begin{array}{l}25 \cdot 4 \\
26 \cdot 7 \\
25 \cdot 5\end{array}$ & $\begin{array}{l}25 \cdot 7 \\
27 \cdot 4 \\
24 \cdot 8 \\
25 \cdot 5\end{array}$ \\
\hline \multicolumn{2}{|c|}{ No. of observations } & & 5 & 4 & 3 & 3 & 3 & 4 \\
\hline \multicolumn{2}{|c|}{ Mean T.E.I. \pm S.D. } & & $22 \cdot 5 \pm 1 \cdot 1$ & $24.4 \pm 0.9$ & $24 \cdot 1 \pm 1 \cdot 3$ & $24 \cdot 3 \pm 0.6$ & $25.9 \pm 0.7$ & $25 \cdot 9 \pm 1 \cdot 1$ \\
\hline
\end{tabular}

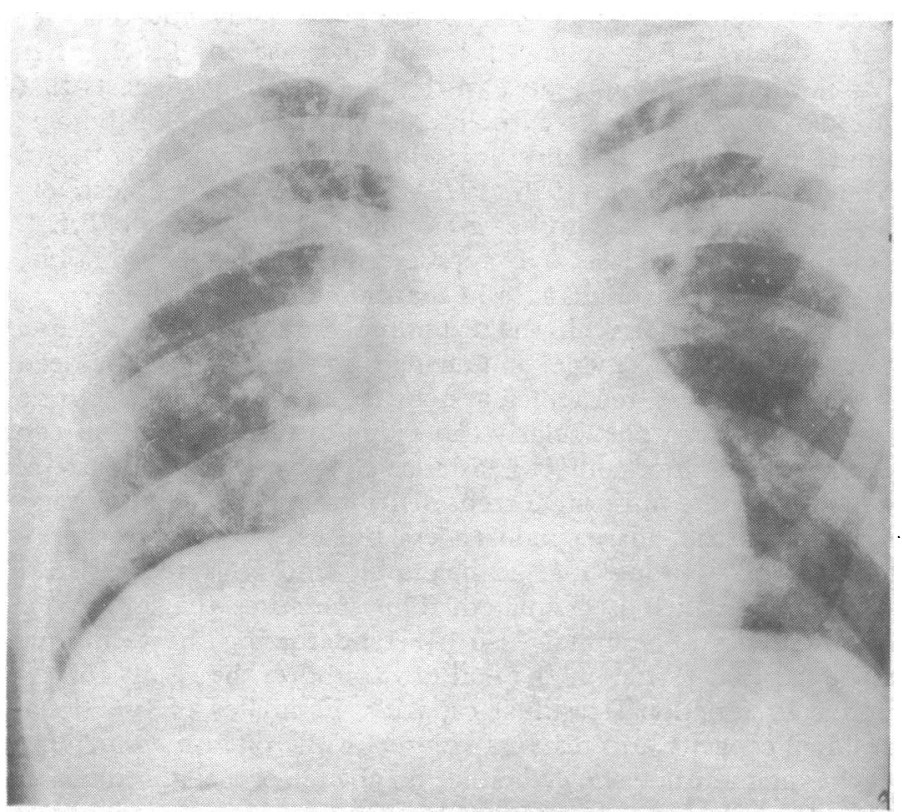

FIG. 3-Subject 5. Chest $x$-ray appearances in subject who developed H.A.P.O. on day after arrival at high altitude when T.E.I. was $21 \cdot 1 \Omega$. Note patchy oedema in right and scattered patches in left hilar area.

$34 \cdot 7 \Omega$ at sea level to $21 \cdot 1 \Omega$. He was given $80 \mathrm{mg}$ of frusemide intravenously and continuous oxygen. After 90 minutes the T.E.I. had increased to $35.5 \Omega$. His symptoms disappeared and he made an uneventful recovery. The serial T.E.I. values are shown in table I and a repeat chest $x$-ray film taken 24 hours later when the T.E.I. was $33.0 \Omega$ is shown in fig. 4 .
Case 2.-A 21-year-old soldier developed throbbing headache, unproductive cough, laboured breathing, excruciating tenderness of the calf muscles, and generalized restlessness on the first day of his return to the high altitude after two months' leave in the plains. The diagnosis was A.M.S. T.E.I. was found to be $21.9 \Omega$. He was given oxygen through a facemask at a rate of $81 . / \mathrm{min}$ for 30 minutes but the T.E.I. remained virtually unchanged $(22 \cdot 6 \Omega)$. Frusemide $40 \mathrm{mg}$ was then given intravenously and after 90 minutes the T.E.I. had risen to

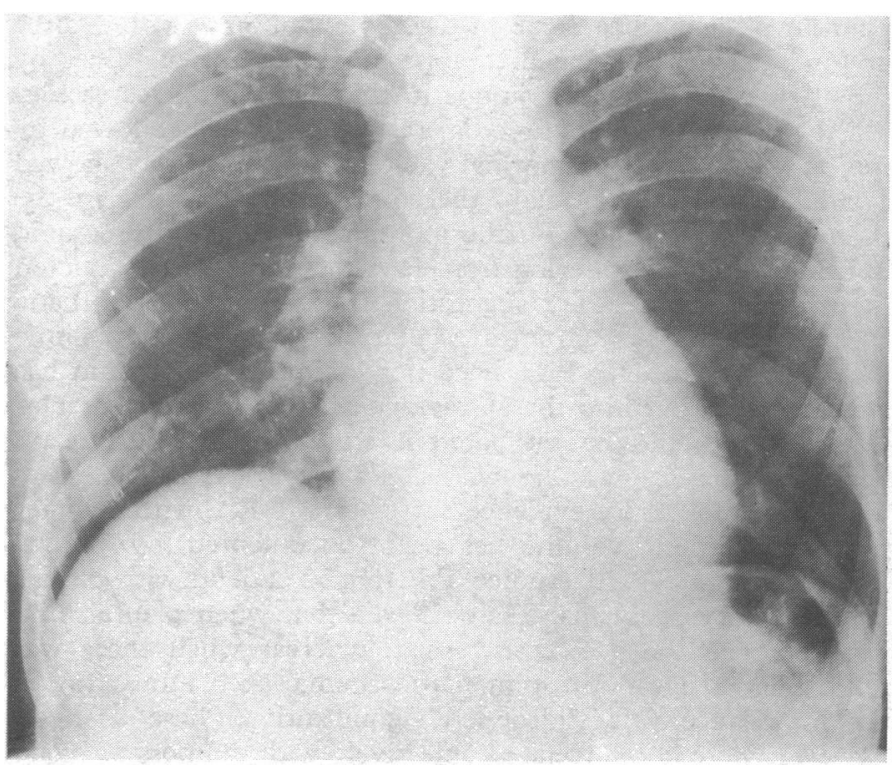

FIG. 4-Subject 5. Chest $x$-ray appearances 24 hours after recovery from H.A.P.O. T.E.I. was 33.0 $\Omega$. The lung fields appear clearer. 
33.2 $\Omega$. Recovery was uneventful. Serial measurements of T.E.I. on three subsequent days were $32 \cdot 1,31 \cdot 6$, and $32 \cdot 0 \Omega$ respectively.

Serial T.E.I. values were obtained in a further five subjects (two with A.M.S. and three with H.A.P.O.) who did not require diuretics (table II). Overall the values were significantly lower $(P<0.0005)$ than those obtained on day 10 in the normal volunteers.

\section{PERMANENT RESIDENTS OF HIGH ALTITUDE}

The mean T.E.I. values in the 13 men permanently resident at high altitudes measured on two occasions were $32.3 \pm 0.7$ and $32 \cdot 1 \pm 0 \cdot 7 \Omega$ respectively (mean $32 \cdot 2 \pm 0 \cdot 7 \Omega$ ) (fig. 2 ). These were significantly different when compared with the sea-level values $(P<0.005)$ but were similar to the values observed in the sealevel residents on the tenth day of their stay at the high altitude $(31 \cdot 5 \pm 0 \cdot 7 \Omega)$.

\section{Discussion}

In this study the mean T.E.I. at sea level in the 20 normal volunteers was $34 \cdot 6 \pm 0.6 \Omega$. Pomerantz et al. (1970) found a normal value of $25 \pm 5 \Omega$. This difference in S.D. is probably due to the fact that our subjects were more of a homogenous group in ethnic origin, age, build, and activities. During the first three days at $3,658 \mathrm{~m}$ the T.E.I. showed a significant fall but by the tenth day the values were comparable to those obtained in 13 permanent residents of high altitude. In persons with H.A.P.O. or A.M.S. the impedance values decreased still further.

Since this was a non-invasive study the decrease in impedance values could not be correlated objectively with increased thoracic fluid volume as shown by changes in pulmonary blood volume or pulmonary extravascular water space. There was, however, some indirect evidence to support such an association. In subject 5 (case 1), who developed H.A.P.O., the radiological appearances of fluid in the lungs coincided with a T.E.I. of $21 \cdot 1 \Omega$. His sea-level value had been $34 \cdot 7 \Omega$. Intravenous frusemide $80 \mathrm{mg}$ was followed by an increase in T.E.I. to $35.5 \Omega$, and next day the lung fields showed definite improvement (figs. 3 and 4). Intravenous frusemide significantly decreases pulmonary blood volume even before diuresis sets in (Bhatia et al., 1969).

In a previous study (Roy et al., 1968) the pulmonary blood volume (determined by a double-catheter technique) in healthy plainsmen airlifted to $3,658 \mathrm{~m}$ rose by about $80 \%$ within three or four days and returned to approximately normal values by the sixth day. Our observations in this study of a decrease in T.E.I. during the first three days at high altitude followed by the recording of almost normal values on the tenth day showed a similar pattern and may, therefore, reflect changes in the thoracic fluid volume. Furthermore, the marked decrease in T.E.I. in subjects suffering from H.A.P.O. or A.M.S. as noted here confirms the earlier suggestion (Roy et al., 1969; Bhatia et al., 1972) that though intravascular pulmonary blood volume measured during H.A.P.O. need not be increased, as fluid has already oozed out into the extravascular space, if extravascular water space could be estimated it would show a significant increase.

More confirmatory evidence correlating T.E.I. with changes in thoracic fluid volume has been documented by others. Pomerantz et al. (1970) studied T.E.I. in 52 patients with cardiac or respiratory problems. They showed that when pleural fluid was removed the T.E.I. increased, whereas when there was pulmonary congestion, pulmonary oedema, or pleural effusion the impedance values dropped significantly. These changes, however, were not correlated objectively with pulmonary blood volume or the pulmonary extravascular water space.

Van De Water et al. (1970) studied T.E.I. in eight women after replacement of the mitral valve and compared the results with various physiological indices. These were pulmonary extravascular water volume, radiological estimation of fluid in the chest, measurement of physiological pulmonary shunts, cardiac output, mean left atrial pressure, central venous pressure, and blood volume. The T.E.I. invariably decreased from preoperative values as a result of pleural, pericardial, or chest wall fluid accumulation. They documented a direct correlation between a rise in impedance and the removal of pleural fluid, an inverse relationship between impedance and the pulmonary extravascular water space, and also a significant drop in impedance in patients with an uncontrolled bleeding diathesis and in whom blood accumulated within the mediastinum, pericardium, and the chest wall though the pulmonary extravascular water space remained normal. Three years later the same group (Van De Water et al., 1973) reported their total clinical experience of monitoring over 200 patients who had undergone heart or lung operations or had pneumonia, pulmonary congestion, heart failure, or pulmonary insufficiency. In every case a drop in impedance was associated with an adverse clinical process. They further argued that instrument failure such as a lose electrode would cause a rise in impedance. For these reasons they emphasized that any fall in impedance was virtually always of clinical importance. It is to be noted that the changes seen in T.E.I. were again not documented by other objective measurements.

No reports are available in which changes in thoracic fluid volume due to high-altitude hypoxia have been estimated by measurement of T.E.I. and correlated with objective measurements such as pulmonary blood volume or pulmonary extravascular water space. In the present series this was not possible as the study was non-invasive. Our observations of a consistent pattern of decrease in T.E.I. during the first three days of exposure to high-altitude hypoxia followed by a gradual rise for seven days to values comparable to those obtained in permanent residents of high altitude, and still lower values of impedance in H.A.P.O. and A.M.S., probably do reflect changes in thoracic fluid volume. Furthermore, in one subject indirect evidence of accumulation of fluid as seen on the chest $x$-ray film together with a low T.E.I. followed by an increase in T.E.I. after frusemide and disappearance of the fluid strongly suggests that the decrease in T.E.I. represented an increase in the thoracic fluid volume. In clinical studies Pomerantz et al. (1970) and Van De Water et al. $(1970,1973)$ have shown this objectively in some patients. It is to be re-emphasized that a single T.E.I. reading is meaningless; only repeated observations on the same subject will indicate changes in the thoracic fluid volume.

Some inherent flaws in the technique of measuring T.E.I. due to respiratory movements and changes in the lung volume need some scrutiny. A tetrapolar system is used to avoid electrode motion artefacts, particularly those due to respiration, that can occur as a result of contact resistance effects in a bipolar system. There is a more uniform current distribution with the tetrapolar system. As the phase angle is less the capacitative resistance component of impedance is negligible and it is the resistive component which is estimated. This measures the ionic conductive mass or volume. Also by standardizing the technique and recording T.E.I. at the end of expiration the result corresponds to functional residual capacity. Estimates of functional residual capacity and residual volume in the plainsmen arriving at the high altitude showed either no change or a slight increase. On the other hand, permanent residents of high altitude have increased levels of functional residual capacity and residual volume (Hurtado, 1964). An increased lung volume would give a higher impedance reading, as is shown in patients with emphysema (Pomerantz et al., 1970). Hence a marked decrease in T.E.I. in subjects exposed to a high altitude is probably not due to either respiratory phase variation or changes in functional residual capacity or residual volume.

T.E.I. when estimated serially in the same subject appears to reflect changes in the thoracic fluid volume when exposed to high-altitude hypoxia. Other workers in clinical studies have 
correlated the changes in impedance values with alterations in the thoracic fluid volume due to pulmonary or cardiac problems. It is suggested that the measurement of T.E.I. is a promising method for the early detection of increased pulmonary fluid volume but that it needs further objective verification in man.

This study was supported by the All India Institute of Medical Sciences, the Directorate General Armed Forces Medical Services, and the Indian Council of Medical Research, New Delhi.

We are grateful to Lt.-Gen. S. N. Chatterjee, Director-General Armed Forces Medical Services, and Lt.-Gen. Ved Prakash, Director Medical Services (Army), and their staff for ungrudging support during all phases of the study.

\section{References}

Allison, R. D., Holmes, E. L., and Nyboer, J. (1964). Gournal of Applied Physiology, 19, 166

Bhatia, M. L., et al. (1969). British Medical fournal, 2, 551.

Bhatia, M. L., et al. (1972). In Advances in Medicine, ed. R. Vishwanathan, p. 466. Bombay, Association of Physicians of India.

Hurtado, A. (1964). In Handbook of Physiology, Section 4, ed. D. B. Dill, E. F. Adolph, and C. G. Wilber, p. 849. Washington, American Physiological Society.

Pomerantz, M., Delgado, P., and Eiseman, B. (1970). Annals of Surgery, 171, 686.

Roy, S. B., et al. (1968). Nature, 217, 1177.

Roy, S. B., et al. (1969). British Heart fournal, 31, 52.

Van De Water, J. M., et al. (1970). Fournal of Thoracic and Cardiovascular Surgery, 60, 641.

Van De Water, J. M., et al. (1973). Chest, 64, 597.

\title{
Hypouricaemia and Proximal Renal Tubular Dysfunction in Acute Myeloid Leukaemia
}

\author{
M. AFZAL MIR, I. W. DELAMORE
}

British Medical fournal, 1974, 3, 775-777

\section{Summary}

Two patients with acute myeloid leukaemia developed hypouricaemia during the period of their illness. Renal clearance studies showed that the hypouricaemia was associated with an increased urate clearance, renal aminoaciduria, and an episodic increase in phosphate clearance. These findings together with an inadequate suppression of urinary urate excretion after the administration of pyrazinamide suggest proximal tubular dysfunction affecting reabsorption of a wide variety of substances. Ten more patients with acute leukaemia were studied and the results indicate that this lesion develops in a large proportion of patients with acute myeloid leukaemia.

\section{Introduction}

An increase in the serum urate level is a common finding in acute leukaemia and lymphoma (Weisberger and Perksy, 1953; Gold and Fritz, 1957; Kritzler, 1958). Hypouricaemia is an unexpected development in diseases characterized by an increase in uric acid production. The case reports of two patients with acute myeloid leukaemia in whom serum uric acid concentration fell below $2 \mathrm{mg} / 100 \mathrm{ml}$ during the course of their illness are presented. Renal clearance studies and amino-acid chromatography showed proximal tubular dysfunction with some features normally seen in association with the adult Fanconi syndrome (Leaf, 1966).

\section{Methods}

Inorganic phosphorus was estimated by the method of Gomorri (1942) using $p$-dimethylaminophenol sulphate as reducing agent. Uric acid and creatinine concentrations were estimated in a Technicon AutoAnalyzer. Paper chromatography was

\footnotetext{
University Department of Clinical Haematology, Manchester Royal Infirmary, Manchester M13 9WL

M. AFZAL MIR, M.R.C.P., D.C.H., Registrar

I. W. DELAMORE, PH.D., F.R.C.P., Physician in Charge
}

performed on the original urine and the extent of aminoaciduria was assessed by visual comparison of the specks with the known spots of various amino-acids. Plasma amino-acid levels were determined by ion-exchange chromatography (Thomas, 1970). Three-hour clearances were performed before and after the administration of pyrazinamide to assess the tubular reabsorption of urate. A high intake of oral fluids was maintained to facilitate spontaneous voiding. Urinary and serum lysozyme concentrations were determined by the turbidimetric method of Parry et al. (1965). Other investigations were performed by standard laboratory methods.

\section{Case Reports}

CASE 1

A 58-year-old woman was admitted to hospital with pallor and moderate hepatosplenomegaly. Haematological studies showed a white cell count of $2,800 / \mathrm{mm}^{3}$ ( $15 \%$ were blast cells), a haemoglobin level of $9 \cdot 1 \mathrm{~g} / 100 \mathrm{ml}$, and a platelet count of $91,000 / \mathrm{mm}^{3}$. A marrow aspirate was hypercellular with $90 \%$ myeloblasts. Serum albumin was $3.5 \mathrm{~g} / 100 \mathrm{ml}$, serum globulin $3.9 \mathrm{~g} / 100 \mathrm{ml}$, serum vitamin $B_{12}$ $277 \mathrm{pg} / \mathrm{ml}$, serum calcium $9.6 \mathrm{mg} / 100 \mathrm{ml}$, and serum inorganic phosphorus $3.4 \mathrm{mg} / 100 \mathrm{ml}$. Serum and urinary muramidase (lysozyme) concentrations were $4.2 \mu \mathrm{g} / \mathrm{ml}$ (normal 3-13 $\mu \mathrm{g} / \mathrm{ml}$ ) and $2.5 \mu \mathrm{g} / \mathrm{ml}$ (normal $<2 \mu \mathrm{g} / \mathrm{ml}$ ) respectively. The blood urea was $28 \mathrm{mg} / 100 \mathrm{ml}$, and three daily serum urate estimations ranged from 4.6 to $5.2 \mathrm{mg} / 100$ $\mathrm{ml}$ (average $4.9 \mathrm{mg} / 100 \mathrm{ml}$ ). Serum transaminases, bilirubin, alkaline phosphatase, and electrolytes were normal. A 24-hour phosphate clearance was $9 \mathrm{ml} / \mathrm{min}$ with a phosphate clearance to creatinine clearance ratio of $0 \cdot 11$ (normal $<0.2$; Nordin and Fraser, 1960). There was no giucosuria, no Bence Jones proteinuria, and the urinary amino-acid chromatographic pattern was normal.

A five-day course of cytotoxic therapy consisting of a single intravenous administration of daunorubicin $(1.5 \mathrm{mg} / \mathrm{kg}$ body weight $)$ and five daily intravenous injections of cytarabine $(2 \mathrm{mg} / \mathrm{kg}$ body weight) was begun on the third day in hospital. Serum urate was $4 \mathrm{mg} / 100 \mathrm{ml}$ and fell to $1.3 \mathrm{mg} / 100 \mathrm{ml}$ two days after the second course of chemotherapy. The results of urate and creatinine clearance studies are shown in table I. Serum calcium was $8.6 \mathrm{mg} / 100 \mathrm{ml}$ and serum inorganic phosphorus $2 \cdot 2 \mathrm{mg} / 100 \mathrm{ml}$. A 24-hour phosphate clearance was $45 \mathrm{ml} / \mathrm{min}$ with a phosphate clearance to creatinine clearance ratio of 0.95 . There was no glucosuria. Paper chromatography showed a generalized aminoaciduria. The arterial blood $\mathrm{pH}$ was $7 \cdot 44$ and serum bicarbonate $28 \mathrm{mEq} / \mathrm{l}$. An acid load of $0.1 \mathrm{~g} / \mathrm{kg}$ body weight of ammonium chloride produced a minimum urinary $\mathrm{pH}$ of 5.3 (normal $\mathrm{pH}<5.3$; Wrong and Davies, 1959). Serum potassium fell to $3 \cdot 2$ $\mathrm{mEq} / \mathrm{l}$. The mean daily potassium output was $42 \mathrm{mEq}$ against an intake of $48 \mathrm{mEq}$. 